\title{
вMJ Global Health Global Surgery 2030: a roadmap for high income country actors
}

To cite: Ng-Kamstra JS, Greenberg SLM, Abdullah F, et al. Global Surgery 2030: a roadmap for high income country actors. BMJ Global Health 2016;1:e000011. doi:10.1136/bmjgh-2015000011

$\mathrm{JN}-\mathrm{K}$ and $\mathrm{SG}$ are joint first authors.

Received 16 November 2015 Revised 6 January 2016 Accepted 19 January 2016

\section{CrossMark}

For numbered affiliations see end of article.

Correspondence to Dr Joshua S Ng-Kamstra; josh.ng@mail.utoronto.ca

Joshua S Ng-Kamstra, ${ }^{1,2}$ Sarah L M Greenberg, ${ }^{2,3}$ Fizan Abdullah,, ${ }^{4,5}$ Vanda Amado, ${ }^{6,7}$ Geoffrey A Anderson, ${ }^{2,8}$ Matchecane Cossa, ${ }^{9}$ Ainhoa Costas-Chavarri, ${ }^{2,10}$ Justine Davies, ${ }^{11}$ Haile T Debas, ${ }^{12,13}$ George S M Dyer, ${ }^{10,14}$ Sarnai Erdene, ${ }^{15}$ Paul E Farmer, ${ }^{16,17}$ Amber Gaumnitz, ${ }^{17}$ Lars Hagander, ${ }^{18}$ Adil Haider, ${ }^{19,20}$ Andrew J M Leather, ${ }^{21}$ Yihan Lin, ${ }^{2,22}$ Robert Marten, ${ }^{23,24}$ Jeffrey T Marvin, ${ }^{17}$ Craig D McClain, ${ }^{25,26}$ John G Meara, ${ }^{2,27}$ Mira Meheš, ${ }^{28}$ Charles Mock, ${ }^{29,30}$ Swagoto Mukhopadhyay, ${ }^{2,31}$ Sergelen Orgoi, ${ }^{32,33}$ Timothy Prestero, ${ }^{34}$ Raymond R Price, ${ }^{35,36}$ Nakul P Raykar, ${ }^{2,37}$ Johanna N Riesel, ${ }^{2,38}$ Robert Riviello, ${ }^{19,39}$ Stephen M Rudy, ${ }^{40}$ Saurabh Saluja, ${ }^{2,41}$ Richard Sullivan, ${ }^{21,42}$ John L Tarpley, ${ }^{43,44}$ Robert H Taylor, ${ }^{45}$ Louis-Franck Telemaque, ${ }^{46,47}$ Gabriel Toma, ${ }^{2}$ Asha Varghese, ${ }^{48}$ Melanie Walker, ${ }^{49}$ Gavin Yamey, ${ }^{50}$ Mark G Shrime ${ }^{2,51}$

\section{ABSTRACT}

The Millennium Development Goals have ended and the Sustainable Development Goals have begun, marking a shift in the global health landscape. The frame of reference has changed from a focus on 8 development priorities to an expansive set of 17 interrelated goals intended to improve the well-being of all people. In this time of change, several groups, including the Lancet Commission on Global Surgery, have brought a critical problem to the fore: 5 billion people lack access to safe, affordable surgical and anaesthesia care when needed. The magnitude of this problem and the world's new focus on strengthening health systems mandate reimagined roles for and renewed commitments from high income country actors in global surgery. To discuss the way forward, on 6 May 2015, the Commission held its North American launch event in Boston, Massachusetts. Panels of experts outlined the current state of knowledge and agreed on the roles of surgical colleges and academic medical centres; trainees and training programmes; academia; global health funders; the biomedical devices industry, and news media and advocacy organisations in building sustainable, resilient surgical systems. This paper summarises these discussions and serves as a consensus statement providing practical advice to these groups. It traces a common policy agenda between major actors and provides a roadmap for maximising benefit to surgical patients worldwide. To close the access gap by 2030, individuals and organisations must work collectively, interprofessionally and globally. High income country actors must abandon colonial narratives and work alongside low and middle income country partners to build the surgical systems of the future.

\section{Key questions}

What is already known about this topic?

- Prior to this work, the magnitude of the burden of surgical disease globally had been established by the Lancet Commission on Global Surgery, the Disease Control Priorities Network, and others. Five billion people lack access to safe, affordable surgical and anaesthesia care when needed and the burden of untreated surgical disease is largely borne by the world's poor.

- The role of high income country (HIC) actors in addressing inequities in surgical care is undergoing evolution and negotiation as the global community transitions from the Millennium Development Goals to the Sustainable Development goals.

What are the new findings?

- This paper brings the acumen of global health experts from a variety of disciplines to bear on how high income country actors such as surgical colleges, academic medical centres, the medical devices industry, and the media can leverage their unique strengths to promote global equity in access to safe surgery and anaesthesia care.

Recommendations for policy

- Expert consensus and a review of the literature yielded common principles for all groups. HIC actors should work in equal partnership with low- and middle-income country actors and should situate efforts to improve the delivery of surgical care within the broader health systems strengthening agenda. This will help to ensure that local priorities are addressed and to maximise synergies with other global health movements. 


\section{INTRODUCTION}

In 1980, Halfdan Mahler, the then Director-General of the WHO, identified surgery as a critical part of primary healthcare and challenged the global health community to address the gross inequities in access to surgical care that were present at that time. ${ }^{1}$ However, over 30 years later, 5 billion people-a number greater than the world's total population at the time of Mahler's speech -are unable to access safe, affordable surgical and anaesthesia care when needed. ${ }^{1-3}$ Concerted action from multiple sectors in all countries is required to ensure that the world will have made progress in closing the access gap by $2030 .^{4}$

Despite clear evidence of the role of surgery in meeting health targets such as reducing maternal and child mortality, surgery was until recently dismissed as a global health priority. ${ }^{5}{ }^{6}$ Since 1990 , non-communicable diseases (NCDs) have attracted only $1.5 \%$ of development assistance for health (DAH), and in 2014 funding for health systems strengthening received only $6.4 \%$ of donor funds. ${ }^{6}$ Country-level spending specific to surgical care remains largely untracked, ${ }^{7}$ but in countries which spend little on health, surgical systems are inadequate for population need..$^{8-10}$

However, the landscape is shifting. While the Millennium Development Goals (MDGs) focused on interventions to improve the well-being of specific populations, the new Sustainable Development Goals (SDGs) aim to improve the well-being of all of humanity through an integrated set of 17 systematic goals. In this context, new evidence has emerged showing that surgical conditions are responsible for nearly one-third of the world's burden of disease, ${ }^{11}$ and that providing surgical treatment can be highly cost-effective. ${ }^{12}$ The Essential Surgery volume of the Third Edition of Disease Control Priorities (DCP-3) identified 44 surgical procedures deemed essential for public health. Authors argued for the early inclusion of surgery within efforts to achieve universal health coverage on the basis of a 10:1 economic benefit: cost ratio. ${ }^{13}$ Targeted funding towards surgery and anaesthesia will be critical to reaching the health-related SDGs: ${ }^{14}$ every Global Burden of Disease subcategory requires surgical intervention at least some of the time. ${ }^{15}$ In completing the 'unfinished business' of the maternal health agenda, ${ }^{16}$ achieving further reductions in child mortality, eliminating extreme poverty, treating the growing burden of NCDs or simply ensuring healthy lives, investing in surgery is imperative.

On 6 May 2015, representatives from around the world gathered in Boston, Massachusetts, for the North American launch of the Lancet Commission on Global Surgery. This launch followed an 18-month research and consensus-building process involving collaborators in over 110 countries. The purpose of this event was twofold: to bring the findings of the Commission to the attention of high income country (HIC) clinicians and policymakers, and to discuss a multicountry, multisectoral approach to improving access to surgery globally.
The launch consisted of panels and presentations addressing the role of various groups: surgical colleges and academic medical centres (AMCs); HIC trainees and training programmes; academia; global health funders; the biomedical devices industry, and news media and advocacy groups. Panelists included members of the global health and global surgery communities, as well as partners in industry, philanthropy and journalism. They represented both HIC and low and middle income country (LMICs) perspectives. This article reviews the relevant literature and provides a unified call to action for each cadre of HIC actors.

\section{COLLEGES AND AMCS: CREATE RESPONSIBILITY FOR ADDRESSING GLOBAL HEALTH INEQUITIES}

The world faces a severe shortage of surgeons, anaesthesiologists and obstetricians (SAO providers). The Commission found that at least 1.27 million new SAO providers will need to be trained by 2030 to reach a conservative benchmark of 20 SAO providers per 100000 population, a target correlated with improved population health outcomes. ${ }^{17}$ Workforce deficits are intensified by unequal distribution of surgical providers, with a greater SAO density in urban, compared with rural, regions. ${ }^{18}$ Therefore, LMIC surgical colleges and AMCs face the dual challenge of training and retaining SAO clinicians where they are most needed.

The primary domestic role of surgical, anaesthesia and obstetric colleges is to encourage and maintain standards for training, continuing professional development and ethical practice to promote quality care and patient safety. ${ }^{19-22}$ Colleges play varied roles in hospital and training programme accreditation processes, which are designed to promote national and regional recognition of these standards. Achieving this recognition can be challenging for colleges in LMICs, as is maintaining funding for college activities. ${ }^{23}$ HIC colleges have partnered with LMIC colleges to overcome these challenges. ${ }^{24}$ The partnership between the Royal College of Surgeons of Ireland (RCSI) and the College of Surgeons of East, Central, and Southern Africa (COSECSA), for example, has led to the implementation of surgical skills courses with a train-the-trainer approach, an online surgical curriculum designed to meet the needs of COSECSA trainees, and a training programme for COSECSA surgeon-scientists. ${ }^{24}$ Using another model, the Royal Australasian College of Surgeons has strengthened surgical training in its region by partnering with the Fiji School of Medicine, Ministries of Health and the Pacific Island Surgical Association. ${ }^{25}$ AMCs serve as a locus for complex clinical care and research, and they have also engaged in the global training effort. ${ }^{26}$ Such engagement has ranged from single-institution relationships to country-wide health workforce initiatives such as Rwanda's Human Resources for Health Program. ${ }^{26} 27$ This programme aims to train over 500 new physicians, treble the number of specialists, bolster the nursing and 
midwifery workforce, and train 150 new health managers over a 7 -year period. ${ }^{27}$ Further research is needed to determine how to maximise the effectiveness of these high-level partnerships in growing a resilient global workforce.

\section{Recommendations for Colleges and AMCs}

- Foster a sense of collective responsibility for addressing global inequities in access to care among surgeons, anaesthesiologists, and the leadership of colleges and AMCs;

- Develop multilevel, long-term relationships with partner organisations to meet global training and continuing professional development needs;

- Create infrastructure, funding mechanisms and career paths to allow HIC surgeons and anaesthesiologists to engage meaningfully in global surgery;

- Engage collectively in solving technical issues related to the evaluation and improvement of quality and safety, for example, by helping to build national surgical outcomes databases;

- Promote health systems and implementation science research relevant to surgery;

- Embrace an interdisciplinary and health systemsfocused approach to building global surgical capacity;

- Promote open communication between colleges across countries and specialties to build synergy of results rather than duplication of efforts.

\section{HIC TRAINEES AND TRAINING PROGRAMIMES: MOVE AWAY FROM SURGICAL COLONIALISM}

Training a strong global workforce will also require the integration of global health into medical and public health curricula. ${ }^{28}$ Roughly $30 \%$ of North American medical students pursue electives in global health, ${ }^{29}$ and up to $94 \%$ of surveyed European medical students desired more global health training. ${ }^{30} 31$ Trends are similar for global surgery. Both Canadian and American surgical trainees are interested in international training opportunities, up to $92 \%$ in one study. ${ }^{32}$ While one study documented that only $13 \%$ of general surgery programmes in the USA offer rotations in global surgery (likely under-reported), this number is growing quickly. ${ }^{34}$ The perceived benefits of surgery rotations in LMICs include exposure to a greater breadth of pathology, learning to manage resource limitations, personal enrichment, appreciating the global burden of surgical disease and bilateral institutional benefits. ${ }^{35} 36$

This type of trainee engagement is not, however, without risks to health systems, patients and trainees and its benefits can be one-sided. In a survey of Ugandan trainees, most agreed that foreign visitors improved their education, but despite conducting research alongside these teams, none had published as a coauthor. ${ }^{37}$ Risks to trainees include occupational exposure to infectious diseases and the lasting negative emotional consequences of witnessing the impact of health systems failures on patients. ${ }^{38} 39$
While it should be noted that these risks are faced by trainees in LMICs on a daily basis, this does not obviate the need for HIC training programmes to take appropriate action to mitigate these when they permit their trainees to travel abroad. HIC trainees may view rotations in LMICs merely as an opportunity to boost case logs, particularly for open (as opposed to laparoscopic) procedures that are less commonly performed in HIC settings. We term this surgical colonialism, a phenomenon that poses a risk to the training experience of LMIC trainees, and there are immediate risks to patient safety if HIC trainees engage in unsupervised work. These risks are only now being quantified in the literature. To minimise harms and maximise benefits, guidelines exist on how HIC individuals at all levels of training should engage in establishing partnerships. ${ }^{40}$ Many training programmes have indeed built rich, academically productive global collaborations. ${ }^{41}$

Internationally, medical students have modelled a particularly enthusiastic and anticolonial approach to health systems and global surgery advocacy. ${ }^{42}$ The International Federation of Medical Students' Associations allows students from around the world to work collectively for sustainable development. Federation membership is priced on a sliding scale using World Bank Income Groups, with a common constitution and by-laws across income groups. To capitalise on trainee enthusiasm, and to provide the infrastructure necessary for sustainable benefit, major universities can create centres for global surgery and contribute to global consortia for health systems strengthening. ${ }^{28} 43$

\section{Recommendations for HIC trainees}

- Develop broad competencies in global health in addition to deep knowledge and skill in an area of specialisation;

- Engage in immersive training in the language and society of partner countries, and approach all new global surgery opportunities with cultural humility;

- Reimagine global health work as long-term relationships rather than as projects limited by time, money and geography;

- Prioritise the clinical and research needs of LMIC partners;

- In the conduct of research, ensure that national colleagues are represented in the conception, design, implementation, analysis, writing and dissemination of results. Include all contributors as authors on any resulting publications;

- When working as a guest in another country, avoid 'surgical colonialism,' stealing surgical cases from local trainees, and conducting unsupervised clinical work.

\section{Recommendations for HIC schools and training programmes}

- Develop and maintain consortia of educational institutions for global surgery and centres of excellence for research, education and advocacy; 
- Build such centres in full partnership with institutions in LMICs, creating space and resources for mutual learning between trainees in HICs and LMICs;

- Consider competency-based and interprofessional models in global health education;

- Endorse global surgery and anaesthesia as established academic career paths for the trainees and the faculty;

- Provide logistical, financial and mentorship support for trainees interested in pursuing global surgery and anaesthesia endeavours;

- Provide opportunities for LMIC trainees to learn, conduct and present research.

\section{ACADEMIA: SUPPORT THE CONDUCT OF RESEARCH BY SURGEONS IN LIMICS}

In the nascent field of global surgery, many knowledge gaps remain. ${ }^{3}{ }^{13}$ Only $4.1 \%$ of global health research activity is surgical, and, of all surgical research worldwide, only $4.3 \%$ is relevant to underserved populations. ${ }^{44}$ While new modelled data are useful for global analyses, primary data are required to make detailed national assessments, evaluate problems and solutions, and track progress. ${ }^{3}{ }^{13}$ This is not possible without the full engagement of surgical researchers in LMICs, but human resources for research in LMICs are lacking. India, Africa and Latin America are home to $42 \%$ of the world's population but only $7.9 \%$ of the world's researchers, ${ }^{45}$ and few new researchers are studying health systems. Despite the great need for health systems strengthening in many sub-Saharan African countries, only $3.8 \%$ of health sciences $\mathrm{PhD}$ students in the region study health services and systems research. ${ }^{46}$ African solutions to these issues exist, including the development of a new Africa Center for Biostatistical Excellence. ${ }^{47}$ This centre is designed to make the region less dependent on foreign statisticians for competitive grant writing, advanced data analysis, publication of health research, and teaching statistics. Furthermore, the INDEPTH Network has taken up the gargantuan task of collecting robust health and demographic data. This is a network of 45 centres in 20 LMICs that actively surveys the health of 3 million people. ${ }^{48}$ The data that this effort will provide will inform health systems strengthening efforts for decades to come.

Surgeons in LMICs who wish to contribute to global surgical research face systemic barriers to conducting research. The most commonly cited barriers are a lack of sustainable funding and protected time for research, a lack of research training, the absence of a culture of research, the competing demands of private practice, and difficulties with record keeping and data management. ${ }^{49}$ Health research capacity strengthening efforts should work to overcome these barriers while addressing disincentives to conducting research, to ensure local ownership of the research and to build trust, cooperation and a locally relevant agenda. ${ }^{50}$ In this spirit, HIC academic surgeons can help build a global network of researchers to make surgical research relevant to all settings.

\section{Recommendations for HIC academic surgeons}

- Engage in sustainable research partnerships and cede first or senior authorship to clinicians who work primarily in the institutions hosting the research;

- Partner with LMIC organisations to help promote training in research methodology;

- Assist with the establishment and maintenance of robust data collection mechanisms for quality improvement and research;

- Spend time in LMIC contexts to develop long-term academic relationships with surgeons in LMICs and understand care delivery challenges;

- Align research priorities with those of national governments and local partners;

- Evaluate solutions to care delivery problems rather than simply describing the problems.

\section{Recommendations for academic journal editors and publishers}

- Encourage submissions of global surgery manuscripts;

- Reduce or eliminate barriers to publication for LMIC authors;

- Help build systems and mechanisms to improve access to knowledge, including by making research relevant to people in LMICs free for them to access and ensuring publication in the language of the country where the research was conducted;

- Ensure authorship properly reflects contributions from LMIC researchers;

- Work with academic institutions to help strengthen the quality of research conducted;

- Educate researchers in all settings on hypothesisdriven, impactful research to improve relevance and reduce research waste;

- Prioritise global surgery research according to its relevance to most of the world's population both in specialist and general medical journals;

- Provide assistance to develop promising manuscripts, and/or develop a partnership model to improve the quality of submitted articles.

\section{GLOBAL HEALTH FUNDERS: RECOGNISE THE HEALTH, WELFARE, AND ECONOMIC BENEFITS OF INVESTING IN SURGERY}

DAH works: In 2014, health economists estimated that with an additional US\$1 billion in health aid, 364800 under 5-deaths could be prevented. This figure was based on health improvements in 140 aid-recipient countries between 1974 and 2010. ${ }^{52}$ With concerted international effort, the maternal mortality ratio fell $45 \%$ between 1990 and $2013 .{ }^{53}$ Improved spending efficiency or accelerated improvement was seen in both of these examples after the year 2000, most likely due to improved technologies and better coordination in the 
context of the MDGs. ${ }^{52} 54$ Projecting forwards from 2015 to 2030, the Lancet Commission on Investing in Health estimated that the economic benefits of investing in health systems and services would exceed costs by a factor of $9-20 .{ }^{55}$

In the context of health systems investments, safe surgery and anaesthesia are a 'best buy' regardless of the economic analysis framework chosen. Simple costeffectiveness analyses reveal that surgery compares favourably with interventions such as antiretroviral therapy for HIV or bed nets for malaria. ${ }^{12}$ Cost-benefit analysis shows that the economic benefits of cleft lip and palate surgery and caesarean section far outweigh the costs. ${ }^{56}$ However, extended cost-effectiveness analysis shows that simply providing free surgery alone provides great health benefits but places the poor at increased risk of medical impoverishment due to the significant non-medical costs of care. ${ }^{57} 58$ Even at present, among those fortunate enough to access surgery, 33 million face catastrophic spending due to the medical costs of accessing surgery and anaesthesia care, and 48 million more are financially devastated by the non-medical costs such as transportation, food and lodging. ${ }^{59}$ Therefore, the costs attendant to getting surgery should be incorporated early into universal health coverage pathways.

Verguet $e t$ al estimated that the cost of scaling up surgical services, at an annual rate of increase of $8.9 \%$ in the number of surgeries performed, between 2012 and 2030 would be about US $\$ 420$ billion. ${ }^{60}$ This cost represents only $1-8 \%$ of current annual health systems spending in LMICs and pales in comparison to the US $\$ 12.3$ trillion economic productivity losses that will be incurred due to surgical conditions without urgent action. ${ }^{3}$ Much of the funding necessary for a surgical scale-up can be mobilised from domestic funds; while DAH was US\$33 billion in 2012, government expenditures on health in LMICs exceeded US\$700 billion. ${ }^{61}$ Even in sub-Saharan Africa, government health expenditures were more than triple the amount of DAH received.

However, the poorest countries simply may not have the required capital to invest in surgery. In these circumstances, external aid will be essential. Between 1990 and 2014, the bulk of DAH came from the US government, followed by private philanthropy and the UK government. ${ }^{6}$ Absolute contributions tell only part of the story; in 1970, the United Nations General Assembly passed a resolution that each developed country would contribute $0.7 \%$ of gross national product to development assistance by $1975 .{ }^{62}$ Unfortunately, over 40 years later, only a handful of countries have met this target. While the absolute contributions of the USA are large, it spends less on development assistance than the average Organisation for Economic Co-operation and Development country proportionally, at $0.19 \%$ of gross national income. ${ }^{63}$

New financing mechanisms and new donor countries show promise in growing the overall funding pool. ${ }^{64}$ For example, the Debt2Health model piloted by the Global Fund may be particularly fruitful in funding health systems strengthening in highly indebted poor countries. ${ }^{65-67}$ This model allows indebted countries to redirect debt repayments towards health initiatives through debt relief agreements with creditor countries. ${ }^{66}$ Furthermore, an ambitious financing facility in support of maternal and child health was announced in July 2015 at the Third International Conference on Financing for Development. ${ }^{68}$ Financing comprehensive health systems with targeted investment for improving surgical capacity will require the same global enthusiasm.

\section{Recommendations for global health funders}

- Recognise that 'surgical care is affordable, saves lives, and promotes economic growth';

- Provide long-term support to allow for sustained health systems strengthening with targeted funding towards safe surgery and anaesthesia;

- Promote the inclusion of surgical care early within universal health coverage pathways;

- Recognise that a surgical option is required to meet targets in most global health endeavours, such as the movement for maternal, newborn, and child health;

- Ensure that all donor funding for health systems strengthening and for specific programmes such as national cancer control plans has surgery as an overt, critical part;

- Fund global surgery research at a level commensurate with the global burden of surgical disease.

\section{INDUSTRY: INVEST IN MARKETS, TECHNOLOGIES AND TECHNICIANS}

Biomedical devices can promote safe, effective surgical and anaesthesia care from diagnosis to discharge. An example that has attracted much attention in recent years is the pulse oximeter, which can decrease the incidence of hypoxaemia during general anaesthesia ${ }^{69}$ and is recommended by the WHO guidelines for safe surgery. ${ }^{70} \mathrm{Up}$ to $70 \%$ of operating rooms in Eastern sub-Saharan Africa lack this basic technology. ${ }^{71}{ }^{72}$ Technological solutions to surgical problems need not be complex or expensive: the non-governmental organisation (NGO) Lifebox has demonstrated that robust, accurate oximeters can be produced economically and at scale. ${ }^{73}$ Technology plays a central role in the delivery of modern surgical care, but there are four salient issues with respect to its optimal use in LMICs: problematic equipment donations, a mismatch between government and NGO purchase requirements and context of use, the challenge of consumables, and the challenge of long-term maintenance.

First, donations of equipment from well-meaning organisations or individuals that do not meet the WHO guidelines fail early or do not meet local needs. The WHO reports that a large majority of this equipment is 
never used. ${ }^{74} 75$ Unused and broken medical equipment causes hundreds of millions of dollars in unacceptable waste and is a barrier to improved health outcomes. ${ }^{76} 77$ Second, whether donated or purchased, equipment considered for use in LMICs must be context appropriate. For example, a large number of hospitals (as many as $64 \%$ in a study of 8 LMICs) do not have consistent electricity available. ${ }^{78}$ While solving upstream infrastructural deficits is important for long-term growth, devices should be able to accommodate the present infrastructure. For situations where existing equipment and devices cannot fulfil the unique needs of LMICs, the process of designing tailored solutions should involve extensive consultation with end-users, as this is critical to promoting correct device use and protecting patient safety. ${ }^{79-81}$ This local engagement can extend to the manufacturing process; HIC-based companies can partner with local organisations to develop and produce equipment to meet regional needs. ${ }^{82}$ In appropriate circumstances, this can stimulate the economy, reduce the costs of production and transport, and improve the reliability of supply. ${ }^{82}$ Third, after clinicians adopt medical devices into clinical practice, regular maintenance must be performed to ensure ongoing availability; in a study of over 110000 pieces of biomedical equipment in LMICs, $40 \%$ was found to be non-functioning. ${ }^{83}$ Most problems with equipment can be solved with a limited set of basic skills and a minimum of spare parts. ${ }^{84} \mathrm{~A}$ programme of biomedical equipment training, which teaches these basic skills has been implemented by Duke University, the GE Foundation and Engineering World Health. In addition to increasing the proportion of working equipment, this programme generates opportunities for skilled employment. ${ }^{79}$ Scaling such training can be facilitated by government investment and hospital commitment to remunerate biomedical technicians fairly. Finally, consumables are components that are intended to be discarded after every use, which in an HIC context might even include surgical instruments and sensor probes. Many equipment donation programmes targeting LMICs focus almost exclusively on the initial purchase cost of a device, as opposed to the long-term cost of consumable components, which in a brief period can exceed many multiples of the original purchase price. ${ }^{76}$ To greatly reduce the cost of ownership, purchasers must demand that partners in industry produce washable and reusable components.

In the light of an estimated 143 million additional procedures required each year and an active scale-up of surgical systems underway in some countries, equipment for surgery has become a growth industry. ${ }^{3} 60$ This growth creates obvious incentives for the private sector to engage in LMIC markets. In doing so, manufacturers have a responsibility to engage in a manner that addresses the needs of health systems, health professionals, patients and investors. Finally, as markets for medical devices develop and change rapidly, the regulatory role of national governments must evolve. ${ }^{85}$ Only
$49 \%$ of countries have a health technology policy, and only $44 \%$ have national lists of medical devices approved for procurement or reimbursement. ${ }^{86}$ Strategies for regulating quality, safety, pricing and use of devices require careful context-specific study and implementation to promote access while avoiding unintended consequences. ${ }^{85}$

\section{Recommendations for the biomedical devices industry}

- Supply, design and manufacture high-quality equipment with the context and end-user in mind;

- Develop and support LMIC biomedical equipment markets;

- Consider manufacturing locally to produce more affordable products, improved profit margins and greater benefit to local economies;

- Support brand-agnostic biomedical equipment training;

- Avoid 'dumping' used, outdated or discontinued devices overseas;

- Support new low-cost innovations for surgery.

\section{PRESS AND ADVOCACY: USE DATA AND PERSONAL STORIES TO DEVELOP PUBLIC SUPPORT}

Strengthening surgical systems globally will require national surgical planning, the inclusion of surgery within basic health coverage packages, generation of external funding where domestic funds are insufficient, and public education to encourage care-seeking when needed. In each of these domains, global surgery stakeholders and the media can play a powerful role in building public and political support.

Media attention to global health problems tends to correlate strongly with funding, although causality in this relationship is unclear. ${ }^{87}$ This may be related to the phenomenon that the public perceives diseases more frequently represented in the media as being of higher severity. ${ }^{8}$ Yet what drives media attention is not the magnitude of a disease's burden on population health. For example, paediatric pneumonia, diarrhoea and measles, which are leading causes of mortality in children, attract far less news coverage than the Global Fund diseases: AIDS, tuberculosis, and malaria. ${ }^{87}$ Similarly, surgical disease has historically attracted little attention from the HIC news media compared with communicable diseases. ${ }^{89}$ Therefore, global surgery advocates must take the lead on actively shifting the current discourse towards the vast global disparity in access to surgical and anaesthesia care. In doing so, global surgery advocates can learn from campaigns for another class of under-reported diseases, the Neglected Tropical Diseases (NTDs). ${ }^{90}$ News stories for these diseases (eg, leishmaniasis) tend to cluster around distinct events such as conferences, scientific breakthroughs and the awarding of large academic grants, and are typically driven by selected journalists with a personal interest in these diseases. ${ }^{90}$ Global 
surgery advocates must engage in concerted, strategic media outreach, and build relationships with informed health reporters.

Gaining political and public awareness requires the pathos that comes with telling the stories of real patients as well as the logos of scientific data. Universities and academics are still the most commonly cited voices in global health reporting. ${ }^{90} 91$ Academic global surgeons, therefore, have an opportunity to illustrate the evidence base for the expansion of surgical care and direct the global action plan to achieve it. Media training can help academic global surgeons achieve the ethos needed to attract attention to the field. Op-Eds are an excellent medium to bring together pathos and logos to seed this ethos, and academic global surgeons have an inherent advantage in securing placement in top-tier national and global media outlets due to their expertise and affiliations.

Finally, collective advocacy will allow for the voices of surgical patients to be heard above the noise of the information age. Over 50 organisations within the global health landscape have come together to form an alliance to advocate for greater political and public health prioritisation of neglected surgical issues. The Global Alliance for Surgical, Obstetric, Trauma, and Anaesthesia Care, or the G4 Alliance, provides a platform for member organisations to advocate for important global surgical issues, bringing structure to existing informal partnerships and collaborations within the global surgical community.

The global surgery and anaesthesia community has a unified message to deliver and has overcome the fragmentation that has sidelined global surgery in the past, both prerequisites to developing domestic and global political priority. ${ }^{92}$ There are now data on the costs and benefits of surgery, ${ }^{3}{ }^{13}$ a cohesive set of demands, ${ }^{93}$ political opportunities for prioritising surgery, ${ }^{14}$ and a set of time-bound targets against which progress can be measured. ${ }^{3}$ These are imperfect and are likely to evolve over the course of the SDGs, but the global advocacy effort must unite behind them to achieve success. While highlighting the ongoing tragedy of the global access gap, there is good reason to communicate optimism towards narrowing it by 2030 .

\section{Recommendations for global surgery advocates}

- Recognise and communicate the enormity of the global burden of surgical disease;

- Investigate and communicate the state of national surgical plans around the world;

- Capitalise on events such as conferences, large grant awards, the publication of major reports, and political decisions to communicate ongoing activity in the field;

- While respecting patient privacy and autonomy, tell the stories of people who still lack surgical and anaesthesia care.

\section{CONCLUSIONS}

Surgical systems are currently developing too slowly to meet population need by $2030 .{ }^{4}$ To accelerate progress, cross-sectoral engagement is required (figure 1). HIC colleges and AMCs can contribute the full power of their training capacity; trainees can engage in collective advocacy and meaningful research; the academic community can help to strengthen surgical research capacity in LMICs; funders can provide the capital required for broad health systems strengthening and a targeted surgical scale-up; the biomedical devices industry can drive sustainable technological innovation, and the press can build public awareness and support.

Dr Jim Yong Kim, President of the World Bank Group, delivered a video address on 6 May 2015, remarking that the Commission 'shows that we have to think in a fundamentally different way about healthcare and surgery's role in it. Not only is (improving) access to surgery the

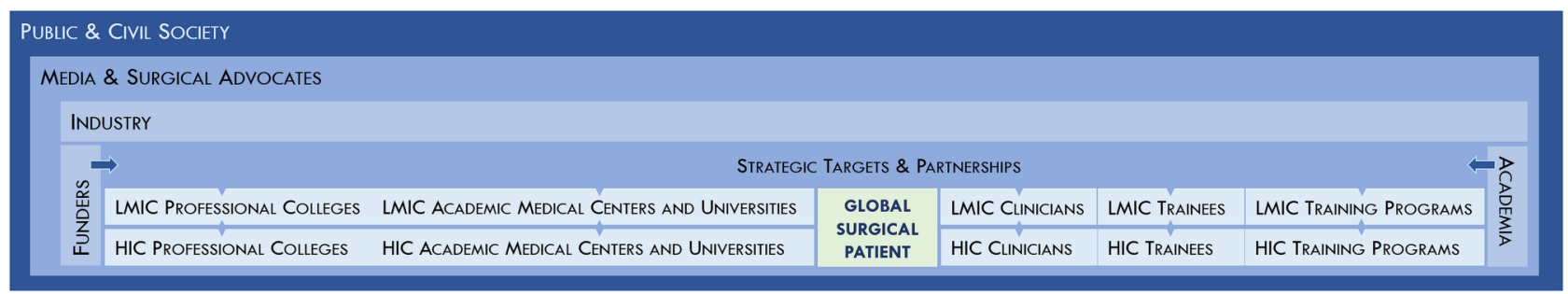

Figure 1 A representation of the inter-relationships between actors in global surgery. In this model, the public and civil society are the ultimate arbiters of universal access to surgery and anaesthesia as a policy priority. The media and surgical advocates provide this group with both data on the state of surgical care worldwide, and quality human interest reporting on the impact this has on individuals. Motivated by the double bottom line of health equity and the potential for expanded markets, the biomedical devices industry can help to solve technological and infrastructural problems related to the delivery of surgical care. This model posits the role of high income country (HIC) surgical actors (colleges, academic medical centres and universities, clinicians, trainees and training programmes) as being partners to their counterparts in low-and-middle income countries (LMICs). Funders can seek strategic opportunities to contribute to the development of surgical infrastructure, training programmes and, more broadly, health systems. Academia in all countries can provide evidence on optimal solutions to care delivery challenges and also help monitor progress towards universal access to safe, affordable surgical and anaesthesia care when needed by 2030. 
right thing to do morally, but it is also important to ending extreme poverty and boosting shared prosperity.$^{94}$ The day's cross-cutting themes were delineated in a keynote address delivered by Dr Paul Farmer. First, the global surgery community should focus on building resilient health systems. Sustainable surgical care implies an operating room and a surgeon, as well as safe anaesthesia care, perioperative nursing care, well-developed training structures, functional equipment, referral systems and equitable financing mechanisms. To that end, advocacy on behalf of global surgery should be integrated with other global health movements. Furthermore, effective advocacy requires both a commitment to improving the evidence on which policy is founded and communicating the individual narratives of those for whom a lack of access to surgical care is a devastating reality. Finally, throughout the discussion, the value of humility and shared responsibility was frequently mentioned, as was a commitment to an accompaniment model to achieve global health equity for surgery. Accompaniment requires a deep understanding of local context and political economy and a firm commitment to walking alongside LMIC partners until the task is completed to their satisfaction..$^{95}$

Following the Commission's initial launches, several critical events have generated momentum. First, in May 2015, 23 surgical and anaesthesia colleges from around the world signed a document in support of the Commission's vision, findings and aims. ${ }^{96}$ Later that month, a WHO resolution on strengthening emergency and essential surgical care was approved by 194 member states during the 68th World Health Assembly. ${ }^{93}$ Furthermore, multiple surgical indicators endorsed by the Commission were included in the WHO's Global Reference List of 100 Core Health Indicators, resulting from an appeal by the international community published in the Lancet and endorsed by the Commission and the G4 Alliance. ${ }^{97}{ }^{98}$ Since this time, country-level data for these indicators have been collected. ${ }^{99}$ This will allow country champions to benchmark surgical care and create national surgical plans to reach targets on all indicators by 2030. The Commission has been launched both in India and in South Africa; further 'National Surgical Forums' are planned to build consensus on the salient problems and policy solutions at the country level in LMICs. No one stakeholder can alone achieve the cross-sectoral improvements required to make timely, universal access to safe, affordable surgical and anaesthesia care a reality. We call on all countries to commit to this vision to achieve the health, welfare, economic and equity gains it promises.

\footnotetext{
Author affiliations

${ }^{1}$ Department of Surgery, University of Toronto, Toronto, Canada

${ }^{2}$ Program in Global Surgery and Social Change, Harvard Medical School and Boston Children's Hospital, Boston, Massachusetts, USA

${ }^{3}$ Department of Surgery, Medical College of Wisconsin, Milwaukee, Wisconsin, USA
}

${ }^{4}$ Department of Surgery, Northwestern University, Feinberg School of Medicine, Chicago, Illinois, USA

${ }^{5}$ Division of Pediatric Surgery, Ann and Robert H. Lurie Children's Hospital of Chicago, Chicago, Illinois, USA

${ }^{6}$ Department of Surgery, Maputo Central Hospital, Maputo, Mozambique

${ }^{7}$ Faculty of Medicine, Eduardo Mondlane University, Maputo, Mozambique

${ }^{8}$ Department of Surgery, Massachusetts General Hospital, Boston,

Massachusetts, USA

${ }^{9}$ National Program of Surgery, Ministry of Health of Mozambique, Maputo,

Mozambique

${ }^{10}$ Department of Surgery, Harvard Medical School, Boston, Massachusetts, USA

${ }^{11}$ The Lancet Diabetes and Endocrinology, London, UK

${ }^{12}$ University of California, San Francisco School of Medicine, San Francisco, California, USA

${ }^{13}$ University of California Global Health Institute, San Francisco, California, USA

${ }^{14}$ Department of Orthopaedic Surgery, Brigham and Women's Hospital,

Boston, Massachusetts, USA

${ }^{15}$ Mongolian National University of Medical Sciences, Ulaanbaatar, Mongolia

${ }^{16}$ Harvard University, Cambridge, Massachusetts, USA

${ }^{17}$ Partners In Health, Boston, Massachusetts, USA

${ }^{18}$ Pediatric Surgery, Department of Clinical Sciences in Lund, Division of Pediatrics, Lund University, Lund, Sweden

${ }^{19}$ Center for Surgery and Public Health, Harvard Medical School and Harvard TH Chan School of Public Health, Boston, Massachusetts, USA

${ }^{20}$ Department of Surgery, Brigham and Women's Hospital, Boston,

Massachusetts, USA

${ }^{21}$ King's Centre for Global Health, King's Health Partners and King's College

London, London, UK

${ }^{22}$ Department of Surgery, University of Colorado Faculty of Medicine, Denver, Colorado, USA

${ }^{23}$ The Rockefeller Foundation, New York, New York, USA

${ }^{24} \mathrm{Global}$ Health and Development, London School of Hygiene and Tropical

Medicine, London, UK

${ }^{25}$ Department of Anaesthesiology, Perioperative and Pain Medicine, Boston Children's Hospital, Boston, Massachusetts, USA

${ }^{26}$ Department of Anaesthesia, Harvard Medical School, Boston,

Massachusetts, USA

${ }^{27}$ Department of Plastic and Oral Surgery, Boston Children's Hospital, Boston, Massachusetts, USA

${ }^{28}$ The G4 Alliance, New York, New York, USA

${ }^{29}$ Department of Global Health, University of Washington, Seattle,

Washington, USA

${ }^{30} \mathrm{Global}$ Injury Section, Harborview Injury Prevention and Research Centre, Seattle, Washington, USA

${ }^{31}$ University of Connecticut School of Medicine Integrated General Surgery

Program, Farmington, Connecticut, USA

${ }^{32}$ Department of Surgery, Mongolian National University of Medical Sciences, Ulaanbaatar, Mongolia

${ }^{33}$ WHO Collaborating Centre for Essential Emergency and Surgical Care (MOG1), Ulaanbaatar, Mongolia

${ }^{34}$ Design that Matters, Salem, Massachusetts, USA

${ }^{35}$ Department of Surgery, Center for Global Surgery, University of Utah School of Medicine, Salt Lake City, Utah, USA

${ }^{36}$ Intermountain Surgical Specialists, Intermountain Healthcare, Salt Lake City, Utah, USA

${ }^{37}$ Department of Surgery, Beth Israel Deaconess Medical Centre, Boston, Massachusetts, USA

${ }^{38}$ Harvard Plastic Surgery Combined Residency Program, Boston,

Massachusetts, USA

${ }^{39}$ Division of Trauma, Burns, and Surgical Critical Care, Brigham and

Women's Hospital, Boston, Massachusetts, USA

${ }^{40}$ Gradian Health Systems Inc, New York, New York, USA

${ }^{41}$ Department of Surgery, Weill Cornell Medicine, New York, New York, USA

${ }^{42}$ Institute of Cancer Policy, King's College London, London, UK

${ }^{43}$ Department of Surgery, Section of Surgical Sciences, Vanderbilt University, Nashville, Tennessee, USA 
${ }^{44}$ Surgical Service, VA Tennessee Valley Health Care System, Nashville, USA ${ }^{45}$ Department of Surgery, Branch for International Surgical Care, University of British Columbia, Vancouver, Canada

${ }^{46}$ Department of Surgery, State Medical School, Port-au-Prince, Haiti

${ }^{47}$ State University Hospital, Port-au-Prince, Haiti

${ }^{48}$ Developing Health Globally, GE Foundation, Fairfield, Connecticut, USA

${ }^{49}$ President's Delivery Unit, World Bank Group, Washington DC, USA

${ }^{50}$ Duke Global Health Institute, Duke University, Durham, North Carolina, USA

${ }^{51}$ Department of Otology and Laryngology and Office of Global Surgery,

Massachusetts Eye and Ear Infirmary, Boston, Massachusetts, USA

Twitter Follow Joshua Ng-Kamstra at @joshngkamstra, Sarah Greenberg at @SLMGreenberg, Jeffrey Marvin at @jeffmarv, Timothy Prestero at @dtm_ tweets and Stephen Rudy at @gradianhealth

Acknowledgements The authors would like to acknowledge Ms Maggie Towne and Ms Jennifer Puccetti for their support in organising the Commission's launch event.

Contributors AH, AC-C, AV, CM, CDM, FA, GY, HTD, JGM, JTM, JLT, JD, L-FT, MGS, MC, PEF, RRP, RM, RR, SE, SO, SMR, TP, RS, AJML, RHT, VA, $\mathrm{LH}, \mathrm{MW}, \mathrm{GSMD}$ and $A G$ provided the intellectual content on which this report is based. JSN-K and SLMG organised the launch event and wrote the manuscript with NPR, JNR, SM, MM, GAA, GT, SS, YL, JGM, JD and MGS. All the authors critically revised the work and approved the final version.

Funding The authors would like to thank the Harvard Medical School Department of Global Health and Social Medicine for hosting the event, and the Rockefeller Foundation for providing travel funding for international speakers

Competing interests $A V$ is director of Developing Health Globally at the GE foundation, the philanthropic organisation of GE. SMR is Chief Executive Officer of Gradian Health Systems, a non-profit medical device company that manufactures and distributes technology for anaesthesia and surgical applications in low income environments.

Provenance and peer review Not commissioned; externally peer reviewed.

Data sharing statement No additional data are available.

Open Access This is an Open Access article distributed in accordance with the Creative Commons Attribution Non Commercial (CC BY-NC 4.0) license, which permits others to distribute, remix, adapt, build upon this work noncommercially, and license their derivative works on different terms, provided the original work is properly cited and the use is non-commercial. See: http:// creativecommons.org/licenses/by-nc/4.0/

\section{REFERENCES}

1. Mahler H. Surgery and Health for All. 1980. http://www.who.int surgery/strategies/Mahler1980speech.pdf?ua=1

2. Alkire BC, Raykar NP, Shrime MG, et al. Global access to surgical care: a modelling study. Lancet Glob Health 2015;3:e316-23.

3. Meara JG, Leather AJ, Hagander L, et al. Global Surgery 2030: evidence and solutions for achieving health, welfare, and economic development. Lancet 2015;386:569-624.

4. Uribe-Leitz T, Esquivel MM, Molina G, et al. Projections for achieving the Lancet Commission Recommended surgical rate of 5000 operations per 100,000 population by region-specific surgical rate estimates. World J Surg 2015;39:2168-72.

5. Hedges JP, Mock CN, Cherian MN. The political economy of emergency and essential surgery in global health. World J Surg 2010;34:2003-6.

6. Dieleman JL, Graves C, Johnson E, et al. Sources and focus of health development assistance, 1990-2014. JAMA 2015;313:2359-68.

7. Dieleman JL, Yamey G, Johnson EK, et al. Tracking global expenditures on surgery: gaps in knowledge hinder progress. Lancet Glob Health 2015;3(Suppl 2):S2-4.

8. The World Bank. World Development Indicators. 2015. http://data. worldbank.org/indicator/SH.XPD.PCAP

9. Groen RS, Samai M, Stewart KA, et al. Untreated surgical conditions in Sierra Leone: a cluster randomised, cross-sectional, countrywide survey. Lancet 2012;380:1082-7.

10. Bolkan HA, Von Schreeb J, Samai MM, et al. Met and unmet needs for surgery in Sierra Leone: a comprehensive, retrospective, countrywide survey from all health care facilities performing operations in 2012. Surgery 2015;157:992-1001.

11. Shrime MG, Bickler SW, Alkire BC, et al. Global burden of surgical disease: an estimation from the provider perspective. Lancet Glob Health 2015;3(Suppl 2):S8-9.

12. Chao TE, Sharma K, Mandigo M, et al. Cost-effectiveness of surgery and its policy implications for global health: a systematic review and analysis. Lancet Glob Health 2014;2:e334-45.

13. Mock CN, Donkor P, Gawande A, et al. Essential surgery: key messages from Disease Control Priorities, 3rd edition. Lancet 2015;385:2209-19.

14. United Nations. Transforming Our World: The 2030 Agenda for Sustainable Development. 2015. https://sustainabledevelopment.un. org/content/documents/7891TRANSFORMING\%200UR\% 20WORLD.pdf

15. Rose J, Chang DC, Weiser TG, et al. The role of surgery in global health: analysis of United States inpatient procedure frequency by condition using the Global Burden of Disease 2010 framework. PLOS ONE 2014;9:e89693.

16. Countdown to 2015. Fulfilling the Health Agenda for Women and Children: The 2014 Report. Geneva, Switzerland: UNICEF, WHO, 2014.

17. Daniels K, Riesel JN, Meara JG. The scale-up of the surgical workforce. Lancet 2015;385(Suppl 2):S41.

18. Atiyeh BS, Gunn SW, Hayek SN. Provision of essential surgery in remote and rural areas of developed as well as low and middle income countries. Int J Surg 2010;8:581-5.

19. American College of Surgeons. About ACS. 2015. https://www.facs. org/about-acs

20. Royal College of Surgeons of Ireland. About RCSI. 2015. http:// www.rcsi.ie/about

21. Royal College of Physicians and Surgeons of Canada. About Us. 2015. http://www.royalcollege.ca/portal/page/portal/rc/about

22. Royal Australasian College of Surgeons. About RACS. 2015. https:// www.surgeons.org/about/

23. COSECSA. College of Surgeons of East, Central, and Southern Africa: Strategic Plan 2012-2014. 2012. http://www.cosecsa.org/test/ uploads/COSECSA\%20Strategic\%20Plan\%20(IX)2012-2014.pdf

24. Royal College of Surgeons of Ireland. RCSI-COSECSA Collaboration Programme. 2015. https://www.rcsi.ie/cosecsa

25. Watters DA, Ewing $\mathrm{H}$, McCaig $\mathrm{E}$. Three phases of the Pacific Islands Project (1995-2010). ANZ J Surg 2012;82:318-24.

26. Riviello R, Ozgediz D, Hsia RY, et al. Role of collaborative academic partnerships in surgical training, education, and provision. World $\mathrm{J}$ Surg 2010;34:459-65.

27. Binagwaho A, Kyamanywa $P$, Farmer PE, et al. The human resources for health program in Rwanda-new partnership. $N$ Engl $J$ Med 2013;369:2054-9.

28. Frenk J, Chen L, Bhutta ZA, et al. Health professionals for a new century: transforming education to strengthen health systems in an interdependent world. Lancet 2010;376:1923-58.

29. Association of American Medical Colleges. Medical Schoo Graduation Questionnaire. 2014. https://www.aamc.org/download/ 397432/data/2014gqallschoolssummaryreport.pdf

30. Ehn S, Agardh A, Holmer H, et al. Global health education in Swedish medical schools. Scand J Public Health 2015;43:687-93.

31. Bozorgmehr K, Schubert K, Menzel-Severing J, et al. Global Health Education: a cross-sectional study among German medical students to identify needs, deficits and potential benefits (part 1 of 2 : mobility patterns \& educational needs and demands). BMC Med Educ 2010;10:66.

32. Powell AC, Casey K, Liewehr DJ, et al. Results of a national survey of surgical resident interest in international experience, electives, and volunteerism. J Am Coll Surg 2009;208:304-12.

33. Matar WY, Trottier DC, Balaa F, et al. Surgical residency training and international volunteerism: a national survey of residents from 2 surgical specialties. Can J Surg 2012;55:S191-9.

34. Knudson MM, Tarpley MJ, Numann PJ. Global surgery opportunities for U.S. surgical residents: an interim report. J Surg Educ 2015;72: e60-5

35. Henry JA, Groen RS, Price RR, et al. The benefits of international rotations to resource-limited settings for U.S. surgery residents. Surgery 2013;153:445-54.

36. Charles AG, Samuel JC, Riviello R, et al. Integrating global health into surgery residency in the United States. J Surg Educ 2015;72: e88-93.

37. Elobu AE, Kintu A, Galukande M, et al. Evaluating international global health collaborations: perspectives from surgery and anesthesia trainees in Uganda. Surgery 2014;155:585-92.

38. Sharafeldin E, Soonawala D, Vandenbroucke JP, et al. Health risks encountered by Dutch medical students during an elective in the 
tropics and the quality and comprehensiveness of pre-and post-travel care. BMC Med Educ 2010;10:89.

39. O'Donnell P, McAuliffe E, O'Donovan D. Unchallenged good intentions: a qualitative study of the experiences of medical students on international health electives to developing countries. Hum Resour Health 2014;12:49.

40. Grimes CE, Maraka J, Kingsnorth AN, et al. Guidelines for surgeons on establishing projects in low-income countries. World J Surg 2013;37:1203-7.

41. Chao TE, Riesel JN, Anderson GA, et al. Building a global surgery initiative through evaluation, collaboration, and training: the Massachusetts General Hospital experience. J Surg Educ 2015;72: e21-8.

42. International Federation of Medical Students' Associations. Access to safe surgery and anesthesia for all. 2014. http://ifmsa.org/ wp-content/uploads/2015/05/2014MMPS_02 Access-to-Safe-Surgery-and-Anaesthesia-for-All.pdf

43. Debas HT. The Emergence and Future of Global Surgery in the United States. JAMA Surg 2015;150:833-4

44. Sullivan R. The State of Research. North American Launch of the Lancet Commission on Global Surgery. Boston, MA, 2015.

45. United Nations Educational Scientific and Cultural Organization. UNESCO Science Report 2010: the current status of science around the world. Paris, France: UNESCO, 2010.

46. Guwatudde D, Bwanga F, Dudley L, et al. Training for health services and systems research in sub-Saharan Africa-a case study at four East and Southern African universities. Hum Resour Health 2013;11:68.

47. Machekano R, Young T, Rusakaniko S, et al. The Africa Center for Biostatistical Excellence: a proposal for enhancing biostatistics capacity for sub-Saharan Africa. Stat Med 2015;34:3481-9.

48. INDEPTH Network. INDEPTH Network: Who We Are. 2015. http:// www.indepth-network.org/index.php?option=com content\&task=view\&id=1621\&Itemid $=1130$

49. Elliott IS, Sonshine DB, Akhavan S, et al. What factors influence the production of orthopaedic research in East Africa? A qualitative analysis of interviews. Clin Orthop Relat Res 2015;473:2120-30.

50. Ager A, Zarowsky C. Balancing the personal, local, institutional, and global: multiple case study and multidimensional scaling analysis of African experiences in addressing complexity and political economy in health research capacity strengthening. Health Res Policy Syst 2015;13:5.

51. Elliott A, Nerima B, Bagaya B, et al. Capacity for science in sub-Saharan Africa. Lancet 2015;385:2435-7.

52. Bendavid E, Bhattacharya J. The relationship of health aid to population health improvements. JAMA Intern Med 2014;174:881-7.

53. UN. The Millennium Development Goals Report 2015. New York, NY: United Nations, 2015.

54. Kassebaum NJ, Bertozzi-Villa A, Coggeshall MS, et al. Global, regional, and national levels and causes of maternal mortality during 1990-2013: a systematic analysis for the Global Burden of Disease Study 2013. Lancet 2014;384:980-1004.

55. Jamison DT, Summers LH, Alleyne G, et al. Global health 2035: a world converging within a generation. Lancet 2013;382:1898-955.

56. Alkire BC, Vincent JR, Meara JG. Benefit-cost analysis for selected surgical interventions in low- and middle-income countries. In: Debas HT, Donkor P, Gawande A, et al, eds. Essential Surgery. Disease Control Priorities. 3rd edn. Washington DC: World Bank, 2015:361-77.

57. Verguet S, Olson ZD, Babigumira JB, et al. Health gains and financial risk protection afforded by public financing of selected interventions in Ethiopia: an extended cost-effectiveness analysis. Lancet Glob Health 2015;3:e288-96.

58. Shrime MG, Verguet S, Johansson KA, et al. Task-sharing or public finance for expanding surgical access in rural Ethiopia: an extended cost-effectiveness analysis. Health Policy Plan 2015. (Published Online First: 29 December 2015).

59. Shrime MG, Dare AJ, Alkire BC, et al. Catastrophic expenditure to pay for surgery worldwide: a modelling study. Lancet Glob Health 2015;3(Suppl 2):S38-44.

60. Verguet S, Alkire BC, Bickler SW, et al. Timing and cost of scaling up surgical services in low-income and middle-income countries from 2012 to 2030: a modelling study. Lancet Glob Health 2015;3 (Suppl 2):S28-37.

61. Institute for Health Metrics and Evaluation. Financing global health 2014: shifts in funding as the MDG era closes. Seattle, WA: IHME, 2015.

62. Organisation for Economic Co-operation and Development. History of the $0.7 \%$ ODA Target. 2002. http://www.oecd.org/dac/stats/ 45539274.pdf
63. Organisation for Economic Co-operation and Development. Table 1: Net Official Development Assistance from DAC and Other Donors in 2014. Preliminary data for 2014. 2015. http://www.oecd.org/dac/ stats/documentupload/ODA\%202014\%20Tables\%20and\%20Charts. pdf

64. Haines A. Development assistance for health: potential contribution to the post-2015 agenda. JAMA 2015;313:2328-30.

65. International Monetary Fund. Debt Relief Under the Heavily Indebted Poor Countries (HIPC) Initiative. 2015. https://www.imf.org/external/ np/exr/contacts/contacts.aspx

66. Integrated Implementation Framework. Debt2Health. 2015. http://iif. un.org/content/debt2health

67. Moon S, Omole O. Development assistance for health: critiques and proposals for change. Centre on Global Health Security Working Group Papers. London, UK: Chatham House, 2013.

68. United Nations. Outcome document of the Third International Conference on Financing for Development: Addis Ababa Action Agenda. Addis Ababa, Ethiopia: UN, 2015.

69. Pedersen T, Nicholson A, Hovhannisyan K, et al. Pulse oximetry for perioperative monitoring. Cochrane Database Syst Rev 2014;3: CD002013.

70. World Health Organization WPS. WHO guidelines for safe surgery: 2009:safe surgery saves lives. Geneva: World Health Organization, 2009.

71. Funk LM, Weiser TG, Berry WR, et al. Global operating theatre distribution and pulse oximetry supply: an estimation from reported data. Lancet 2010;376:1055-61.

72. LeBrun DG, Chackungal S, Chao TE, et al. Prioritizing essential surgery and safe anesthesia for the Post-2015 Development Agenda: operative capacities of 78 district hospitals in 7 low- and middle-income countries. Surgery 2014;155:365-73.

73. Dubowitz G, Breyer K, Lipnick M, et al. Accuracy of the Lifebox pulse oximeter during hypoxia in healthy volunteers. Anaesthesia 2013;68:1220-3.

74. World Health Organization. Guidelines for Health Care Equipment Donations. Geneva, Switzerland: WHO, EalfPEOoHSD, 2000.

75. World Health Organization. Medical Device Donations: considerations for solicitation and provision. Geneva, Switzerland: WHO, 2011.

76. World Health Organization. Barriers to innovation in the field of medical devices. Geneva, Switzerland: WHO, 2010.

77. The World Bank. HNP Brief \#8: an overview of medical device policy and regulation. Washington DC: The World Bank, 2007.

78. Kushner AL, Cherian MN, Noel L, et al. Addressing the Millennium Development Goals from a surgical perspective: essential surgery and anesthesia in 8 low- and middle-income countries. Arch Surg 2010;145:154-9.

79. Malkin R, Whittle C. Biomedical equipment technician capacity building using a unique evidence-based curriculum improves healthcare. J Clin Eng 2014;39:37-44.

80. Design that Matters. Essay \#6: Listening in the Hardest Market: Equipping a local social enterprise to communicate ideas using prototypes. 2014. http://www.designthatmatters.org/blog/? tag=Lemelson20th

81. Rosen MA, Sampson JB, Jackson EV Jr, et al. Failure mode and effects analysis of the universal anaesthesia machine in two tertiary care hospitals in Sierra Leone. Br J Anaesth 2014;113: 410-15.

82. World Health Organization. Local production and technology transfer to increase access to medical devices: addressing the barriers and challenges in low- and middle-income countries. Geneva, Switzerland: WHO, 2012:17.

83. Perry L, Malkin R. Effectiveness of medical equipment donations to improve health systems: how much medical equipment is broken in the developing world? Med Biol Eng Comput 2011;49:719-22.

84. Malkin R, Keane A. Evidence-based approach to the maintenance of laboratory and medical equipment in resource-poor settings. Med Biol Eng Comput 2010;48:721-6.

85. Bloom $\mathrm{G}$, Henson S, Peters $\mathrm{DH}$. Innovation in regulation of rapidly changing health markets. Global Health 2014;10:53.

86. World Health Organization. Global Health Observatory Data. Medical devices: analysis of results of the baseline country survey, 2013 update 2013. http://www.who.int/gho/health_technologies/medical_ devices/en/

87. Hudacek DL, Kuruvilla S, Kim N, et al. Analyzing media coverage of the global fund diseases compared with lower funded diseases (childhood pneumonia, diarrhea and measles). PLOS ONE 2011;6: e20438.

88. Young ME, Norman GR, Humphreys KR. Medicine in the popular press: the influence of the media on perceptions of disease. PLOS ONE 2008;3:e3552. 
89. McCool J, Cussen A, Ameratunga S. Media reporting of global health issues and events in New Zealand daily newspapers. Health Promot J Austr 2011;22:228-30.

90. Balasegaram M, Balasegaram S, Malvy D, et al. Neglected diseases in the news: a content analysis of recent international media coverage focussing on leishmaniasis and trypanosomiasis. PLOS Negl Trop Dis 2008;2:e234.

91. Verma G. Analysis of the mass media coverage of the Gates Foundation grand challenges in global health initiative. J Med Ethics 2009;35:163-7.

92. Shawar YR, Shiffman J, Spiegel DA. Generation of political priority for global surgery: a qualitative policy analysis. Lancet Glob Health 2015;3:e487-95.

93. WHA. WHA 68.15. Strengthening emergency and essential surgical care and anaesthesia as a component of universal health coverage. Geneva, Switzerland: World Health Association, 2015.
94. Kim J. Opening address: the North American launch of the Lancet Commission on Global Surgery. Boston, USA, 2015.

95. Farmer PE. Accompaniment in Aid Delivery: A Concept Note. 2012. http://www.lessonsfromhaiti.org/download/Report_Center/ accompaniment-in-aid-deliverycon

96. RACS. Surgical Colleges Support the Lancet Commission on Global Surgery. 2015. http://www.surgeons.org/news/ surgical-colleges-support-the-lancet-commission-on-global-surgery/

97. Makasa EM. Letter to global health agency leaders on the importance of surgical indicators. Lancet 2014;384: 1748.

98. WHO. Global Reference List of 100 Core Health Indicators, 2015. 2015. http://www.who.int/healthinfo/indicators/2015/en/

99. Lancet Commission on Global Surgery. Data for the sustainable development of surgical systems: a global collaboration. 2015. http:// www.lancetglobalsurgery.org/\#! indicators/o217z 